Article

\title{
Sustainable or a Butterfly Effect in Global Tourism? Nexus of Pandemic Fatigue, COVID-19-Branded Destination Safety, Travel Stimulus Incentives, and Post-Pandemic Revenge Travel
}

\author{
Umer Zaman ${ }^{1, *(\mathbb{D}}$, Syed Hassan Raza ${ }^{2}\left(\mathbb{D}\right.$, Saba Abbasi ${ }^{3}$, Murat Aktan ${ }^{4}\left(\mathbb{D}\right.$ and Pablo Farías ${ }^{5}(\mathbb{D}$ \\ 1 Endicott College of International Studies (ECIS), Woosong University, Daejeon 34606, Korea \\ 2 Department of Communication Studies, Bahauddin Zakariya University, Multan 66000, Pakistan; \\ hassansherazi@bzu.edu.pk \\ 3 Department of Management Sciences, National University of Modern Languages (NUML), Islamabad 44000, \\ Pakistan; abbasi.saba56@gmail.com \\ 4 Faculty of Economics and Administrative Sciences, Mugla Sitki Kocman University, Mugla 88000, Turkey; \\ murataktan@mu.edu.tr \\ 5 Departamento de Administración, Facultad de Economía y Negocios, Universidad de Chile, \\ Santiago 8330015, Chile; pfarias@fen.uchile.cl \\ * Correspondence: umerzaman@endicott.ac.kr
}

Citation: Zaman, U.; Raza, S.H.; Abbasi, S.; Aktan, M.; Farías, P. Sustainable or a Butterfly Effect in Global Tourism? Nexus of Pandemic Fatigue, COVID-19-Branded Destination Safety, Travel Stimulus Incentives, and Post-Pandemic Revenge Travel. Sustainability 2021, 13, 12834. https://doi.org/10.3390/ su132212834

Academic Editors: Seul Ki Lee and Ian Sutherland

Received: 2 November 2021

Accepted: 17 November 2021

Published: 19 November 2021

Publisher's Note: MDPI stays neutral with regard to jurisdictional claims in published maps and institutional affiliations.

Copyright: (c) 2021 by the authors. Licensee MDPI, Basel, Switzerland. This article is an open access article distributed under the terms and conditions of the Creative Commons Attribution (CC BY) license (https:/ / creativecommons.org/licenses/by/ $4.0 /)$.
Abstract: Revenge travel has globally emerged as a dominant touristic behavior, signaling a rapid return of global tourism, but with a greater temptation for spending more and staying longer. Despite the expanding focus on global sustainable tourism, there is a lack of empirical evidence on the potential factors that build momentum for revenge travel. The aim of the present study was to develop and test a conceptualized model of revenge travel under the influence of pandemic fatigue, COVID-19-branded destination safety, and travel stimulus incentives. Drawing on the study data of international expats $(\mathrm{N}=422)$ and using covariance-based structural equation modeling (CB-SEM), the findings provide new evidence that revenge travel is significantly and positively influenced by pandemic fatigue. Interestingly, the empirical findings also support two positive moderations, highlighting that COVID-19-branded destination safety (CBDS) and travel stimulus incentives (TI) can significantly increase the impact of pandemic fatigue (PF) on revenge travel (RT). Based on prominent theories (i.e., theory of planned behavior, protection motivation theory, and incentive theory of motivation) and newly developed scales (i.e., RT, CBDS, and TI), the study highlights the dynamics of revenge travel as it sets the stage for global tourism to rebound stronger than ever. The implications include new challenges and ways forward through revenge travel as a stepping stone for global sustainable tourism.

Keywords: revenge travel; global sustainable tourism; pandemic fatigue; COVID-19-branded destination safety; travel stimulus incentives; theory of planned behavior; protection motivation theory; incentive theory of motivation

\section{Introduction}

The global tourism industry's sustainable future has been challenged by the COVID-19 pandemic, which has endangered the wellness and lives of tens of thousands of individuals globally. Despite the pandemic initially being associated with Eastern Asian countries, it has had a disproportionate impact, especially on the underprivileged and less developed nations. Therefore, the pandemic forced many governments to face and deal with serious risks [1] and implement various countermeasures (e.g., restrictions on social activities, travel, and tourism, etc.). Eventually, global tourism nearly came to a halt, parallel to other industries, at a level that has not occurred since the second world war. Even domestic traveling ceased in some countries to prevent the spread of the pandemic [2]. These developments have urged families and individuals to explore alternative and safer tourism 
options, which led to the birth of revenge travel [3]. Revenge travel characterizes a recent tourism behavior where individuals travel to escape from the psychological pressure, daily routines, and rules that resulted from the pandemic. The tendency to participate in RT has also accelerated due to long-prolonged lockdowns, curfews, and strictly applied health measures [4]. After following a repetitive routine of staying indoors and being unable to roam outside, most people wanted to make up for the lost time and relieve pandemic fatigue by rushing toward local and international tourism destinations [5]. In particular, despite the shrinkage by $38 \%$ in 2020 , the European tourism industry has experienced a sudden growth of more than $32 \%$ in 2021 . These developments have altered tourism behavior, where revenge travelers' motivations could differ from those before the pandemic [6].

Revenge travelers' choices are influenced by many factors, including COVID-19branded destination safety (CBDS) and travel incentives (TI) offered by the destinations. CBDS is a marketing practice to promote tourism destinations as safe havens from the risks of the pandemic, which ultimately lures away travelers from other competitive destinations. Thus, destinations implementing CBDS strategies are expected to receive a higher number of tourists than other tourism spots, as it occurred in the case of New Zealand [7]. Similarly, implementing travel incentives can be helpful in attracting tourists and providing an initial boost and recovery to the industry. For instance, some well-known destinations, including Japan, Italy, Cyprus, and the Maldives, have recently relied on travel incentive programs that are tailored to meet the current pandemic situations [8]. Global tourism is highly influenced by the traveling habits and assessment of foreigners living abroad. Owing to a substantial $3.2 \%$ of the world's population $[9,10]$, foreign diasporas (i.e., global expats) play a vital role in redefining destinations as international attraction centers. Furthermore, the fact that expats are considered reliable sources of information has turned expats into invaluable partners in destinations' international branding efforts [11]. The expats' key role is even amplified for developing countries that are mostly associated with political turmoil and armed conflicts $[12,13]$. As an emerging economy that has recently suffered from political conflicts, Pakistan was still ranked among the top tourism destinations in 2020 by top-tier travel magazines and bloggers (e.g., The British Backpacker Society, and Forbes, etc.) before the pandemic outbreak [14-18]. However, parallel to the rest of the world, Pakistan also received its share of the deadly virus, and the tourism industry was hit worse by the pandemic, resulting in a loss equivalent to USD 3.24 billion in the gross domestic product (GDP) [19]. Due to the government's effective policies and timely preventive measures to fight the spread of the pandemic, the country suffered less and recovered earlier in contrast to the rest of South Asian tourism destinations [20].

Although a plethora of research has recently approached post-pandemic tourism from different angles [2,21,22], more research on tourism is needed to unveil tourists' complex decision-making and behavior during the COVID-19 pandemic [3,22]. Thus, the aim of this study was to make a novel contribution to the COVID-19 tourism literature by empirically assessing the interrelationships between the most recent trends (i.e., pandemic fatigue, travel incentives, revenge travel, and CBDS) that can potentially predict the future of global tourism [3]. In particular, the present study was an investigation into the relevance of PF from the lens of tourism marketing literature for the first time. Using dominant theories (e.g., theory of planned behavior, protection motivation theory, and incentive theory of motivation) and newly developed scales (i.e., RT, CBDS, and TI), the aim of the present study was to develop and validate a conceptual model of revenge travel under the influence of pandemic fatigue, COVID-19-branded destination safety, and travel incentives. In addition to finding new evidence on the potential impact of PF on RT, the present study was also aimed at examining whether CBDS and travel incentives can significantly influence the PF-RT relationship as contextual moderators. 


\section{Theoretical Background and Hypothesis Development}

\subsection{Pandemic Fatigue}

As defined by the World Health Organization [23], pandemic fatigue (i.e., a broader term for lockdown fatigue) is defined as reasonable and predictable reactions of individuals to lasting and unresolved catastrophes. PF pertains to a sensation of alienation, stress, and low morale, and it progressively evolves under the impact of many factors, including personal experiences, culture, social life, and institutions [24]. PF has been scholarly investigated from different angles, including health, compliance with applied measures, and so on. [25-28]. Labrague [25] comprehensively illustrated the impact of PF on clinical nurses' work satisfaction and mental and cardiovascular health. In another recent study, MacIntyre et al. [27] suggested that PF is linked with individuals' age groups, and younger persons were found to experience more PF.

As stated shortly above, PF impairs people's emotions and mental health, which leads to behavioral changes to adapt to the so-called new normal. Therefore, the pandemic has caused permanent shifts in consumers' buying behaviors, consumer choices, as well as business models [29]. In particular, due to perceived uncertainties and prolonged lockdowns, consumers have developed different patterns to control their emotions and well-being. For instance, most consumers have become familiar with new websites for shopping, changed their once most frequented grocery stores, and embraced alternative consumption patterns [30,31]. PF has brought disruption to economic social activities in the tourism industry. After long lockdowns, people began to see traveling as an escape from the daily routines and the psychological burden of the pandemic [32]. Consequently, PF has changed people's travel choices, as many people have flocked into distant, rural locations where they could stay away from the pandemic and spend time in nature [33].

\subsection{Revenge Travel}

"Revenge travel" is a visitor's excursion following the COVID-19 epidemic after months of remaining at home. This tendency can restore tourism with a shock. The notion of revenge travel emerges from the concept of 1980's revenge spending in China sparked by decades of economic paralysis and poverty. Revenge travel is based on the belief that visitors regard their trip as a vengeance on the pandemic (i.e., reactions fueled by forced lockdowns, quarantines and social distancing) and to compensate for their lost travel time [34]. Several studies have been carried out to examine the consequences and causes of revenge travel [3,35-38]. In a study investigating the feasibility of eco-tourism operations in Mount Putri Bandung, Indonesia, revenge travel was noted to be affecting the future of the tourism industry [35]. In particular, by utilizing qualitative approaches for data collection, the authors revealed that Mount Putri Bandung is an appropriate destination for RT, as it encourages individuals to get out and appreciate the beauty of nature and the fresh air at the destination.

In another study, Abdullah [37] identified the general justifications for COVID-19's prospective fruitful post-pandemic tourist activities. The results revealed that revenge travel is quite likely due to the boredom of most individuals. Some informants indicated they would travel after the pandemic and others said they would travel once a vaccine had been developed. This study may be employed on current tourism research topics, in particular, the post-pandemic tourist activities and the effect of COVID-19. Sudjana et al. [38] conducted research to identify tourists' enthusiasm in the "revenge travel" epidemic of COVID-19. The test subjects were individuals dispersed throughout Indonesia, and a sample of at least 100 participants was used. The results indicated that DI-Yogyakarta, Labuan Bajo, and Bali were three of the most pursued locations following the epidemic.

\subsection{COVID-19-Branded Destination Safety}

COVID-19-branded destination safety is the branding of a tourism destination for COVID-19 safety, and it is a fusion of two concepts, that is, destination branding and destination safety. Firstly, destination branding defines geographical regions, such as 
tourist attractions, as being brand-centered. It is a matter of placing the destination brand with a properly defined brand identity attractively, convincingly, and distinctively in the tourism industry. To tourists, the targeted branding identifies, delineates, and differentiates a location and conveys its image in its appeal to make it a unique and appealing destination for travelers. The safety of tourism largely refers to the personal security and safety of visitors, including the capacity of persons to focus on the foreign surroundings and understand the local sign systems and social customs, as well as the security of purchasing and related industries. Several researchers have recently highlighted the significance of COVID-19-branded destination safety [39-44] to attract international tourism.

During the COVID-19 pandemic, Setiadi et al. [41] assessed the application of the smart tourism branding idea in Bantul Town, Indonesia. The results revealed that the evaluation of smart tourism offers an overview of the level of tourist comprehension and satisfaction during the COVID-19 pandemic. The management of the tourism and branding identity of the city may also be facilitated and enhanced if the community and city stakeholders' synergy plan is properly regulated. Marine-Roig and Huertas [45] conducted a study through language recognition, frequency analysis, and an online term categorizer to assess whether online images viewed and shared by more than 150,000 visitors were negatively affected by the terrorist attack in August 2017 or the Catalan sovereignty process in Barcelona in the last quarter of 2017. The results demonstrate that, despite the seriousness and the huge international coverage of both incidents, tourists were not scared for their safety.

Zou and Meng [43] proposed a conceptual framework of the sense of safety of visitors, encompassing their expected and experienced security. In this study, we surveyed domestic visitors who visited Xiamen, China to assess the predicted safety and experience of tourists. The study was mainly focused on different factors of the expected and experienced safety of tourists, including safety concerns, tourism environment, services and facilities, regional culture, and safety data. In general, the experienced security of tourists exceeded their expectations, and when travelers visited Xiamen, they usually felt safe. To start a larger conversation about the under-investigated importance of brands in crises, Pasquinelli et al. [40] offered insight into the relationship between major brand building and the COVID19 dilemma. Of specific concern to tourist cities is the shift to more sustainable growth, although this is not a given. By examining the phases of branding through communication, participation, and action circuits, branding may provide a lens for observing this possible shift.

\subsection{Travel Incentives}

Travel incentives are the different forms of advantages offered or given to tourists by governments through national tourism policies, tourism business through promotional offers and discounts, and transportation services through discounted or no fares. The main objective of implementing travel incentives as a national or business policy is to attract tourists and provide an initial thrust to the post-pandemic tourism industry by luring as many visitors as possible [46]. Countries in which the tourism industry acts as a major contributor to GDP (such as Maldives, Japan, Italy, Cyprus, Canada, UK, etc.) have adopted different forms of incentive schemes to restart the industry after the COVID-19 pandemic. At first, these incentive schemes might look like an economic loss, but, in a longer perceptive, luring more and more tourists will contribute toward influencing consumer behaviors, increased profits, improved cash flows and customer engagement, and increased tourist flux.

As identified by Singh [8], Sicily (a town in Italy) alone faced a loss of USD 1.09 billion due to zero tourism during the pandemic. To make up for this loss, the local authorities have reduced air ticket prices to half and have offered one-night free accommodation on every three-night booking. Similarly, the Mexican government introduced a travel incentive scheme, namely "Cancun $2 \times 1$ ", which will get tourists a free one-night stay for every two-night booking in the city. Likewise, Canadian authorities are offering a 20\% 
refund (up to a maximum worth of USD 1000) for all costs on vacations in the country. Moreover, the Maldivian government has announced exclusive discounts, special offers, and privileges as part of a loyalty program, "Maldives Border Miles" [47]. The author also mentions Japan, where discounts of up to $35 \%$ of travel costs are being offered by the authorities under a project named "Go-To Travel". STR [48] conducted an impact analysis of this project and confirmed that different tourism hubs of Japan (like Kanto, Tohoku, and Chugoku) observed occupancy rates of more than 53\%, and $43 \%$ for Japan, overall. However, the trend dropped due to the third wave of COVID-19 and the project was discontinued by the government in December 2020. Jones [49] reported one of the most interesting incentives offered by the Cyprus government, covering all the accommodation, food and drinks, and hospitalization or medication costs for tourists and their families who get infected with COVID-19 during their vacation on the island. The author also reported a private business owner in Las Vegas who offered 1000 free flights to the city as an attempt to attract tourists. Other countries like Greece, Portugal, Iceland, and the United States are also offering different travel incentive schemes [50]. Irrespective of the type, host country, and duration of the incentive scheme, the major objective was observed to be common for all- to attract visitors and tourists toward the destinations to support and stimulate the tourism industry and, thus, the national GDP through revenues from the industry.

\subsection{Pandemic Fatigue and Revenge Travel}

After the outbreak of the COVID-19 pandemic in the second half of 2019, every nation started implementing policies and strategies to tackle the deadly disease. One thing that was common among all the national policies was social restrictions involving traveling, dining, and gathering, as well as other restrictions. These restrictions forced people from every field of life to be locked up in the house or to at least minimize social interactions. These unwanted and unavoidable circumstances led to psychological and even physical health issues mainly triggered by pandemic fatigue, as assessed by many researchers [51-53]. Narrowing down the scenario to tourism and the hospitality industry, international flights were called off by every nation and even inter-state traveling was banned in some countries. Public and tourism spots were closed temporarily in the wake to fight the spread of COVID-19. The severe impact of the pandemic on domestic and international tourism combined with social restriction forced amateur and professional tourists around the world to stay at home and stay safe. This also induced pandemic fatigue in the tourism and traveling community, as identified by Wachyuni and Kusumaningrum [5]. Secondly, a plethora of researchers [2,54-56] predicted or identified a boom in the domestic and international tourism of many countries and regarded this post-pandemic tourism spike as "revenge travel". When all of the traveling restrictions end, most professional and amateur travelers are expected to go on trips to make up for their time spent locked inside their homes.

The indication of pandemic fatigue in mid-pandemic times and the prediction of a post-pandemic tourism spike points toward a probable relation between pandemic fatigue and revenge travel. However, no specific study could be found that identifies the exact relationship between these constructs. In this study, we hypothesized a relationship between pandemic fatigue and revenge travel that is referred to as $\mathrm{H}_{1}$. This hypothesis can be theoretically supported with the theory of planned behavior [57].

The theory of planned behavior articulates that individuals' behaviors and intentions are the product of attitudes, social norms, and one's perceived control over his/her behavior. In the early stages of the pandemic, the infection was perceived as deadly and very dangerous, thus resulting in a negative attitude toward traveling. Consequently, traveling was temporarily suspended to ensure safety and avoid health risks. However, after the flattening of the COVID-19 peaks, tourists presumably felt that the danger was significantly reduced. In addition, the fact that health and travel restrictions were relaxed meant that individuals could feel that they had more control over their decisions and behaviors than in the earlier stages of the pandemic. Consequently, once barely leaving their homes, pandemic-fatigued people might come to have great enthusiasm about travel again due to 
the lessened restrictions and increased perceived behavioral control [58]. Based on these arguments, the first hypothesis of the study was created.

Hypothesis 1 (H1). Pandemic fatigue has a significant positive effect on revenge travel.

\subsection{Moderating Effects of CBDS}

COVID-19-branded destination safety (CBDS) emerges from an amalgamation of two concepts of tourism destination management, that is, destination branding and destination safety. As revenge travel continues to appear as the new normal of the tourism industry, the general practices in the tourism industry have also evolved to meet the changing trends. The idea of promoting and branding a tourism destination as a place safe from COVID-19 instead of the conventional promotion of a spot-to attract the revenge travelers out on adventures and endeavors-is known as CBDS. Rating destinations as safe from COVID-19 not only attracts those travelers who are already on their journey to a tourism spot but also pulls in tourists who are still reluctant to plan tours and trips for fear of the virus.

The theoretical support for this hypothesis was taken from protection motivation theory [59], which explains human behavior and decision-making in times of any threat. It proposes that human choices and decision-making under the influence of any danger or threat can be based on the perceived threat and human's ability to cope or deal with it. In particular, CBDS could positively bolster individuals' travel intentions by decreasing their perceived vulnerability and the severity of the COVID-19 situation in destinations. Secondly, Maslow's hierarchy of needs [60] presents safety as the basic need for motivation and personality of a human being. Influenced by safety assurance, as presented in CBDS, tourists are more likely to plan their trips to a destination they perceive as safe from COVID-19. This fuels the motivation behind branding a destination as "COVID-19 safe" instead of conventional promotions in a pandemic or post-pandemic time.

Hypothesis 2 (H2). COVID-19-branded destination safety significantly moderates the relationship between pandemic fatigue and revenge travel.

\subsection{Moderating Effects of Travel Incentives}

Travel incentives generally cover a wide range of offers made by either any organization to employees or from any traveling and tourism-related business to tourists. It can include discount packages, promotional offers, free tours, and so on. Most of the organizations offer incentive traveling opportunities to their employees as a motivation boosting technique or reward scheme, as identified by recent studies [61,62]. In normal conditions, travel incentives are offered to enhance the tourism flux, but in post-pandemic conditions, when people experience fatigue and are likely to practice revenge travel, travel incentives can act as boosters as well as inhibitors of the trend. When offered by tourism and travel services, TIs can enhance and induce revenge travel within the tourist and, thus, act as boosters, while when offered to employees by their organizations, it can replace revenge travel for those who are fatigued by the pandemic and act as inhibitors. This dual nature of TIs suggests their moderating effect on the relationship between PF and RT. This hypothesized relationship is theoretically supported by the incentive theory of motivation [63], which proposes that the choices of individuals are likely to be influenced by the incentives (both intrinsic and extrinsic). In particular, the fact that destinations provide incentives and rewards will likely boost the extent to which pandemic-fatigued individuals want to travel in a pandemic.

Hypothesis 3 (H3). Travel incentives significantly moderate the relationship between pandemic fatigue and revenge travel. 


\section{Methods}

\subsection{Sampling and Procedure}

The present study was aimed at empirically examining a conceptualized model of revenge travel under the influence of pandemic fatigue, COVID-19-branded destination safety, and travel incentives. Due to an unknown (and/or not specifically reported) population of international expats residing in various provinces and cities of Pakistan, as well as the challenge of data collection during times of the COVID-19 pandemic crisis, the present study adopted the recommended approach of non-probability sampling that ensured the cost-effective and timely collection of the study data $[11,64]$. Using a standardized questionnaire, the study data on international expats were mainly collected through direct emails (i.e., sharing an online survey) to the expat's community, as well as multiple social media platforms (e.g., Facebook, LinkedIn, and WhatsApp, etc.) and very few in-person (i.e., face-to-face) interactions due to strict COVID-19 restrictions. Foreign diplomats and staff members of international organizations located across Pakistan, especially those residing in the capital (Islamabad) and the cities of Lahore and Karachi, were contacted through direct emails, which were accessed through their official websites. On social media platforms, groups and pages dedicated to foreigner communities in Pakistan were accessed to distribute the link to the online expat's survey, while some Pakistan-based international NGOs and donor organizations housing a larger group of expats (e.g., the Asian Development Bank and the United Nations Development Programme, etc.) were also approached. Thus, a combination of snowballing (i.e., chain referral) and judgmental (i.e., purposive) sampling techniques were utilized. These approaches have been proven effective for data collection from foreign communities in prominent studies [11,65]. In the initial invitation, the confidentiality and anonymity associated with their participation were clearly communicated to all interested expats, as well as a request to forward and share the survey within their expat community (i.e., colleagues, friends, and family) residing in Pakistan. The international expat community residing in Pakistan delivered the initial pool $(\mathrm{N}=450)$ of volunteer expats. However, after an initial analysis, some responses were excluded from the study to ensure data normality and the necessary removal of outliers. The final sample size $(\mathrm{N}=422)$ showed an exceptional response rate $(93.7 \%)$ according to the metrics suggested by literature [66]. Importantly, recommended procedures were also adopted during the survey (e.g., ensuring anonymity, confidentiality, and promising feedback to the respondents who had no knowledge about the study's conceptual model, as well as ensuring a simplified survey with easily understandable questions) to overcome any issue of common method bias [11,64].

\subsection{Measures}

In this study, we developed new scales to measure the variables included in the study based on the guidance of the prior literature $[26,34,43,49,67]$. While developing the scales, interviews were held with senior academics/professors and industry practitioners, along with conducting an extensive literature search. Furthermore, the internal reliability and validity of all the scales were verified with the help of statistical tests. To measure pandemic fatigue, 10-items were adapted from the work of Lilleholt et al. [26]. The scale contained items that pertained to respondents' felt exhaustion due to COVID-19 regulations and restrictions, their continuous fear of getting an infection, and the negative psychological influence of media and public discussions about COVID-19. For the RT, a new scale was generated based on the prominent literature $[34,36-39,42,43]$. The CBDS scale contained items that pertained to perceived destination safety, COVID-19-free ambiance provided by destinations, and factors involved in destination choices during the pandemic. Last but not least, to measure travel incentives, a 9-item scale was also developed from prior studies $[44,46,49,50]$. All latent constructs (item-wise details are described in the Appendix A) were scored on a 5-point Likert scale, where 1 indicates strong disagreement and 5 indicates strong agreement. 


\subsection{Data Analysis}

The covariance-based structural equation modeling (CB-SEM) technique was utilized for the empirical analysis of the hypothesized relations and conceptual model built on them. Literary evidence suggests that SEM can be implemented with quite a small sample size [68,69], but some studies have recommended a minimum sample of 100-150 participants for reliable outcomes of the technique [69,70]. AMOS software was used for SEM analysis of the collected data in the context of hypothesized relationships, structural, and conceptual models. Recently, there has been a lot of research focused on the CB-SEM technique and its best applications. However, multiple studies have suggested using the SEM technique according to the nature of variables and collected data, and the advantage of CB-SEM has been highlighted over other methods for which greater internal reliability of stronger path coefficients are required [71-73]. SEM has been extensively used in social and cognitive research $[11,74,75]$, while CB-SEM is one of the emerging techniques of SEM, showing potential for future applications in the research work.

\section{Results}

\subsection{Descriptive Statistics}

Table 1 shows the descriptive statistics and correlation matrix of the variables included in the study. The mean responses of the four variables, that is, RT, CBDS, PF, and TI, were estimated as $3.804,3.443,4.233$, and 3.849 , respectively, which reflects that the respondents expressed a higher degree of agreement with pandemic fatigue experience in contrast to other variables. Similarly, CBDS was least regarded as travel motivation by the respondents, while the same variable had the highest standard deviation (0.788) from the mean response, indicating that the responses differed most for this variable. A high Cronbach's alpha value $(\mathrm{RT}=0.86, \mathrm{CBDS}=0.94, \mathrm{PF}=0.88, \mathrm{TI}=0.82)$ indicates good internal consistency of the constructs [76]. From the correlation matrix, it can be assessed that all the variables were positively related to each other; however, TI shows no or a low correlation with RT (0.062) and PF (0.013), and PF shows no or a low correlation with CBDS (0.058). At the same time, RT was moderately associated with CBDS (0.265) and PF (0.275). In addition, the two moderating variables, CBDS and TI, exhibited the highest positive association (0.528).

Table 1. Descriptive and correlation analysis $(\mathrm{N}=422)$.

\begin{tabular}{cccccccc}
\hline Constructs & $\mathbf{M}$ & $\mathbf{S D}$ & $\boldsymbol{\alpha}$ & $\mathbf{R T}$ & $\mathbf{C B D S}$ & $\mathbf{P F}$ & TI \\
\hline RT & 3.804 & 0.599 & 0.86 & 1 & & & \\
CBDS & 3.443 & 0.788 & 0.94 & 0.265 & 1 & & \\
PF & 4.233 & 0.623 & 0.88 & 0.275 & 0.058 & 1 & \\
TI & 3.849 & 0.738 & 0.82 & 0.062 & 0.528 & 0.013 & 1 \\
\hline
\end{tabular}

Note-RT: revenge travel, CBDS: COVID-19-branded destination safety, PF: pandemic fatigue, and TI: travel incentive.

\subsection{Sampling Adequacy}

The Kaiser-Meyer-Olkin (KMO) measure of sampling adequacy test [77] and Bartlett's test of sphericity [78] were used to assess whether the variable and data are useful for factor analysis. The KMO test statistic refers to the variance proportion within the variables that can be triggered due to different factors. Data with higher KMO statistic values (closer to 1) are adequate for factor analysis, and the outcomes of factor analysis are deemed useful. Similarly, data with lower values of significance (smaller than 0.05) in Bartlett's test are generally classified as useful data for factor analysis. Table 2 presents the results of the KMO and Bartlett's test, which indicate that the data and variables used in this research were adequate for the factor analysis. 
Table 2. KMO and Bartlett's Test $(\mathrm{N}=422)$.

\begin{tabular}{ccc}
\hline \multicolumn{2}{c}{ Kaiser-Meyer-Olkin Measure of Sampling Adequacy } & $\mathbf{0 . 8 8 3}$ \\
\hline Bartlett's Test of Sphericity & Approx. Chi-Square & $28,055.779$ \\
& df & 703 \\
& Sig. & 0.000 \\
\hline
\end{tabular}

\subsection{Exploratory Factor Analysis}

Exploratory factor analysis (EFA) is a statistical technique used in multivariate analysis for determining a measure's construct validity and assessing its internal reliability. Principal component analysis was used as the factor extraction method, and the varimax rotation method with Kaiser normalization [79] was used to simplify and clarify the structural model (see Table 3). It can be noted that all the items yielded a rotated factor loading greater than 0.6 , indicating the construct's internal reliability and acceptable factor structure, as suggested by Awang et al. [80]. Additionally, Herman's single factor test was conducted to detect and assess the common method variance (CMV). Following this statistical technique, we introduced all items of underpinned variables into an EFA by employing the unrotated factor solution. During this procedure, we examined the extracted factors with eigenvalues higher than 1 that provided estimations for the cumulative variance. We followed the recommended criteria that if CMV exists, only one factor would have accounted for more than $50 \%$. The results of Herman's test confirmed that CMV was non-existent, as the single factor structure demonstrated only $37.9 \%$ variance [81,82].

Table 3. Exploratory factor analysis $(\mathrm{N}=422)$.

\begin{tabular}{|c|c|c|c|c|}
\hline & 1 & 2 & 3 & 4 \\
\hline CBDS1 & 0.872 & & & \\
\hline CBDS2 & 0.907 & & & \\
\hline CBDS3 & 0.860 & & & \\
\hline CBDS4 & 0.847 & & & \\
\hline CBDS5 & 0.828 & & & \\
\hline CBDS6 & 0.879 & & & \\
\hline CBDS7 & 0.910 & & & \\
\hline CBDS8 & 0.888 & & & \\
\hline CBDS9 & 0.901 & & & \\
\hline CBDS10 & 0.883 & & & \\
\hline RT1 & & 0.945 & & \\
\hline RT2 & & 0.921 & & \\
\hline RT3 & & 0.932 & & \\
\hline RT4 & & 0.903 & & \\
\hline RT5 & & 0.925 & & \\
\hline RT6 & & 0.868 & & \\
\hline RT7 & & 0.907 & & \\
\hline RT8 & & 0.898 & & \\
\hline RT9 & & 0.943 & & \\
\hline PF1 & & & 0.961 & \\
\hline PF2 & & & 0.868 & \\
\hline PF3 & & & 0.927 & \\
\hline PF4 & & & 0.673 & \\
\hline PF5 & & & 0.953 & \\
\hline PF6 & & & 0.916 & \\
\hline PF7 & & & 0.938 & \\
\hline PF8 & & & 0.912 & \\
\hline PF9 & & & 0.952 & \\
\hline
\end{tabular}


Table 3. Cont.

\begin{tabular}{|c|c|c|c|c|}
\hline & 1 & 2 & 3 & 4 \\
\hline TI1 & & & & 0.938 \\
\hline TI2 & & & & 0.885 \\
\hline TI3 & & & & 0.810 \\
\hline TI4 & & & & 0.896 \\
\hline TI5 & & & & 0.678 \\
\hline TI6 & & & & 0.887 \\
\hline TI7 & & & & 0.900 \\
\hline TI8 & & & & 0.927 \\
\hline TI9 & & & & 0.887 \\
\hline
\end{tabular}

Note-Extraction method: Principal component analysis. Rotation method: Varimax with Kaiser normalization Rotation converged in 5 iterations.

\subsection{Confirmatory Factor Analysis}

As suggested by Brown [83], confirmatory factor analysis (CFA) evaluates the consistency of measures included in the constructs with the general understanding of the nature of the construct. CFA indicates the degree to which the available data are suitable for the proposed measurement model. In Table 4, it can be observed that most of the items included in the four constructs have standardized factor loading values $(\lambda)$ greater than the threshold value of 0.7 , which indicates the data and measures are suitable for the model. Only three items, namely, PF4, PF9, and TI5, have $\lambda$ values less than 0.7 , which were omitted from the construct to achieve model fitness.

Table 4. Confirmatory factor analysis $(\mathrm{N}=422)$.

\begin{tabular}{|c|c|c|c|c|}
\hline Items & CBDS & RT & PF & TI \\
\hline CBDS1 & 0.79 & & & \\
\hline CBDS2 & 0.89 & & & \\
\hline CBDS3 & 0.82 & & & \\
\hline CBDS4 & 0.78 & & & \\
\hline CBDS5 & 0.76 & & & \\
\hline CBDS6 & 0.87 & & & \\
\hline CBDS7 & 0.84 & & & \\
\hline CBDS8 & 0.91 & & & \\
\hline CBDS9 & 0.73 & & & \\
\hline CBDS10 & 0.88 & & & \\
\hline RT1 & & 0.77 & & \\
\hline RT2 & & 0.91 & & \\
\hline RT3 & & 0.83 & & \\
\hline RT4 & & 0.81 & & \\
\hline RT5 & & 0.90 & & \\
\hline RT6 & & 0.85 & & \\
\hline RT7 & & 0.88 & & \\
\hline RT8 & & 0.87 & & \\
\hline RT9 & & 0.79 & & \\
\hline PF1 & & & 0.84 & \\
\hline PF2 & & & 0.80 & \\
\hline PF3 & & & 0.91 & \\
\hline PF4 & & & $0.62 *$ & \\
\hline PF5 & & & 0.87 & \\
\hline PF6 & & & 0.86 & \\
\hline PF7 & & & 0.96 & \\
\hline PF8 & & & 0.88 & \\
\hline PF9 & & & 0.53 * & \\
\hline
\end{tabular}


Table 4. Cont.

\begin{tabular}{cccc}
\hline Items & CBDS & RT & PF \\
\hline TI1 & & TI \\
TI2 & & 0.96 \\
TI3 & & 0.84 \\
TI4 & & 0.86 \\
TI5 & & 0.88 \\
TI6 & & $0.68^{*}$ \\
TI7 & & 0.89 \\
TI8 & & 0.87 \\
TI9 & & 0.90 \\
\hline
\end{tabular}

${ }^{*}$ Items deleted-3 items were omitted to achieve model fitness (PF4, PF9, and TI5).

Figure 1 shows the measurement model with the standardized factor loading for each item denoted on the relevant construct. It can also be noted that the three items with lower factor loading values were removed from the model.

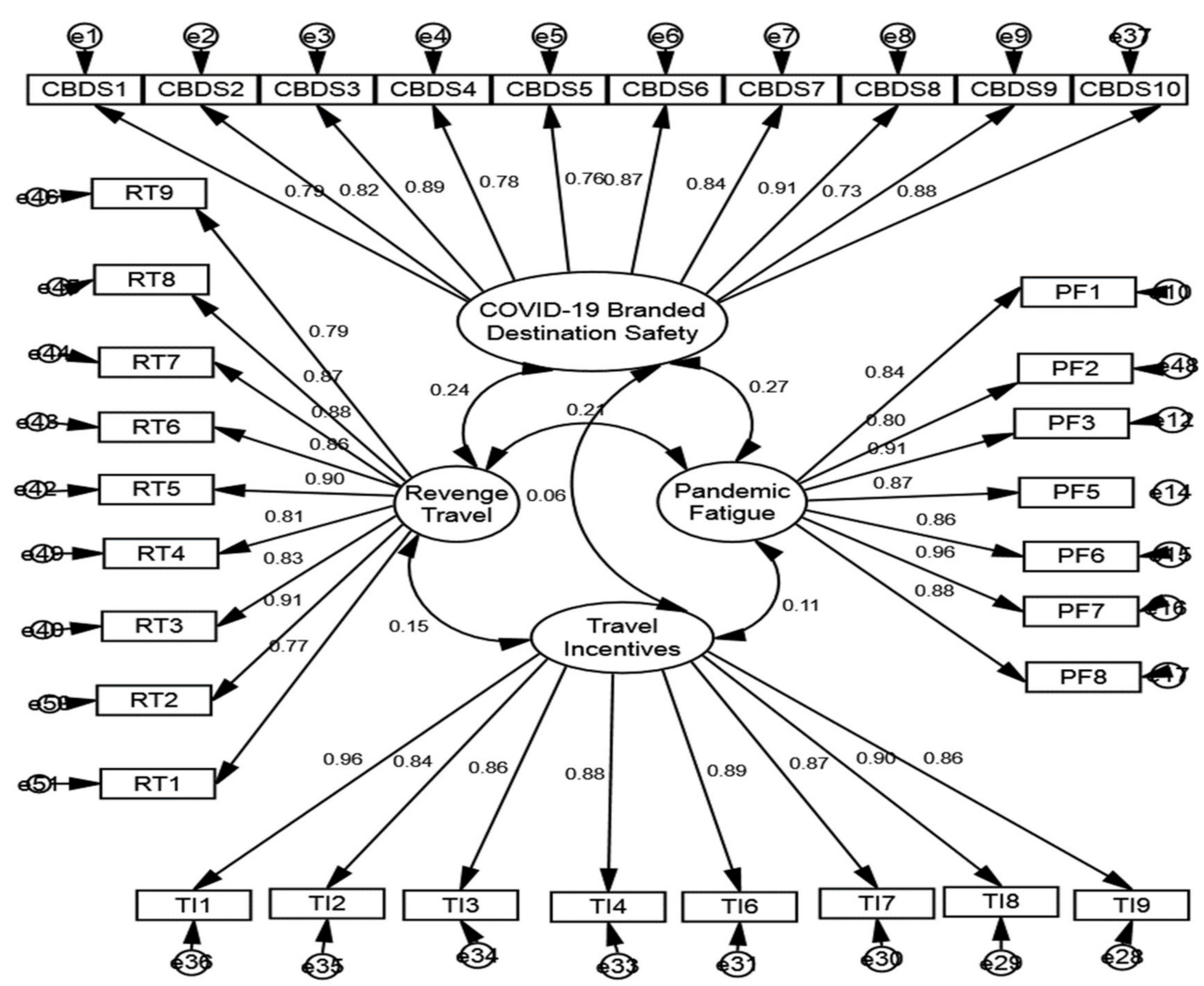

Figure 1. Measurement model.

\subsection{Convergent and Discriminant Validity}

The convergent and discriminant validity of the construct was also measured in the analysis. Table 5 presents the summary of outcomes; it can be noted that the composite reliability (CR) value for each construct is greater than 0.7 , which indicates the internal reliability of all the items included in these constructs. Moreover, the average variance extracted (AVE) values are also greater than 0.5 , as asserted by $[74,83]$.

Similarly, the diagonal values representing the square root of the AVE (parentheses values) are greater than the non-diagonal values, which consolidates the proof of discriminant validity of the construct, ensuring that no issues of multicollinearity exist between the 
constructs. Proved convergent validity means that the constructs that are expected to have a relationship are actually related, while discriminant validity confirms that constructs that should not be related to each other are not related.

Table 5. Convergent and divergent validity $(\mathrm{N}=422)$.

\begin{tabular}{ccccccc}
\hline Constructs & CR & AVE & RT & CBDS & PF & TI \\
\hline RT & 0.95 & 0.68 & $(0.824)$ & & & \\
CBDS & 0.96 & 0.72 & 0.24 & $(0.85)$ & & \\
PF & 0.95 & 0.76 & 0.21 & 0.27 & $(0.87)$ & \\
TI & 0.96 & 0.77 & 0.15 & 0.06 & 0.11 & $(0.88)$
\end{tabular}

Note-AVE: Average variance extracted, CR: composite reliability. Values in parentheses represent the square root of AVE.

\subsection{Measurement of Model Fit Indices}

The model fit measures for both models, the measurement model and the structural equation model, were calculated. It was observed that the model fit indices yielded higher values for both models. As shown in Table 6, the fit index values for the measurement model are $0.95,0.97,0.97$, and 0.96 for NFI, IFI, CFI, and TLI, respectively. For the structural equation model, these values are $0.99,0.99,0.99$, and 0.98 , respectively. These higher values indicate an acceptable model fit for the measurement and structural equation models [84,85]. Moreover, the RMSEA values were also observed to be in range $(<0.6)$ for both models, which also indicates the fair fit of the models [82]. The RMSEA value for the measurement model was observed to be slightly greater than the upper limit of an acceptable range. The SRMR values for both models were observed to be in range (0-1) and lower than the recommended cut-off value $(<0.8)$, thus indicating a good fit of the models [86].

Table 6. Model fit indices $(\mathrm{N}=422)$.

\begin{tabular}{ccccccccc}
\hline Model & $x^{\mathbf{2}}$ & $x^{\mathbf{2}} / \mathbf{d f}$ & NFI & IFI & CFI & TLI & RMSEA & SRMR \\
\hline Measurement Model & 1330.269 & 2.74 & 0.95 & 0.97 & 0.97 & 0.96 & 0.064 & 0.038 \\
Structural Model & 967.71 & 30.16 & 0.99 & 0.99 & 0.99 & 0.98 & 0.047 & 0.033 \\
\hline
\end{tabular}

\subsection{Structural Equation Model}

Testing of the hypotheses was consequently done after attaining a positive correlation between the variables. The path coefficients of the structural models and the relationship between the included latent constructs were determined by covariance-based SEM using AMOS $[87,88]$. Table 7 provides a summary of the relationships between the PF, RT, CBDS, and TI. It also presents the outcomes of pertinent hypotheses of the study with path coefficient values $(\beta)$, t-statistic values, and $p$-values. Hypothesis $\mathrm{H} 1$ was confirmed on the base of Structural Model 1, where the path coefficient value for the relationship between PF and RT was found to be positive, which indicates a positive relationship between the two variables, as hypothesized in the study. A higher $t$-value (10.164) indicates that the relationship between the two variables is significant. As the $t$-value is greater than the critical value, the null hypothesis is considered rejected. Similarly, a lower $p$-value ( $p$-value $<0.05)$ for the relationship indicates the significance of the strength of the pertinent hypothesis (H1). Similarly, the moderating hypotheses were tested using Model 2, where positive path coefficients indicate a positive moderating effect of both CBDS (H2) and TI (H3) on the relationship between PF and RT. Likewise, the $t$-values of 3.990 and 4.725 indicate the significance of $\mathrm{H} 2$ and $\mathrm{H} 3$, respectively, and lower $p$-values ( $p$-values $<0.05$ ) reflect the significance of the estimated moderating strength of CBDS and TI. These findings provide strong evidence to support all three hypotheses of this study. Moreover, it can be observed that the variance in RT increased from 34\% to 39\% (R-squared increased from 0.34 to 0.39 ) due to the inclusion of the moderating variables CBDS and TI in the model, which also consolidates the evidence of the moderating effects of CBDS and TI. 
Table 7. SEM testing hypothesized results $(\mathrm{N}=422)$.

\begin{tabular}{cccccc}
\hline Model Paths & $\boldsymbol{\beta}$ & $\boldsymbol{t}$-Value & $\boldsymbol{p}$ & $\mathbf{R}^{\mathbf{2}}$ & Hypotheses/Outcomes \\
\hline Model 1 & & & & & \\
PF $\rightarrow$ RT & 0.40 & 10.164 & 0.001 & 0.34 & $\mathrm{H}_{1}$ Accepted \\
CBDS $\rightarrow$ RT & 0.23 & 9.831 & 0.001 & & \\
TI $\rightarrow$ RT & 0.16 & 3.968 & 0.001 & & \\
Model 2 & & & & & \\
PF $\rightarrow$ RT & 0.49 & 12.840 & 0.001 & 0.39 & \\
CBDS-X-PF $\rightarrow$ RT & 0.15 & 3.990 & 0.001 & & $\mathrm{H}_{2}$ Accepted \\
TI-X-PF $\rightarrow$ RT & 0.18 & 4.725 & 0.001 & & $\mathrm{H}_{3}$ Accepted \\
\hline
\end{tabular}

Note-RT: Revenge travel, CBDS: COVID-19-branded destination safety, PF: pandemic fatigue, and TI: travel incentive.

Figure 2 shows Structural Model 1 when employed without moderators. Path coefficient for each relationship can also be observed in the figure showing the same model with the effect of the moderators, where it can be observed that the path coefficient values changed under the influence of the moderators. It can be noted from the figures that the values of the path coefficients in Figure 3 are moderated in Structural Model 2, into which moderating variables were incorporated. This statistical evidence reflects the effectiveness of the CB-SEM technique [89] and authenticates the moderating effect of CBDS and TI. Confirmation of $\mathrm{H} 1$ indicates that revenge travel is expected to emerge as a tourism trend in regions where COVID-19 halted social and interpersonal interactions. In addition, this trend can intensify in areas with long-lasting lockdowns or strict COVID-19 protocols and restrictions. Similarly, $\mathrm{H} 2$ and $\mathrm{H} 3$ indicate that the implementation of CBDS and TI strategies, respectively, can reinforce the emergence of RT in response to PF (the $\beta$-coefficient increases from 0.40 to 0.49 ), as shown in Figures 2 and 3, respectively.

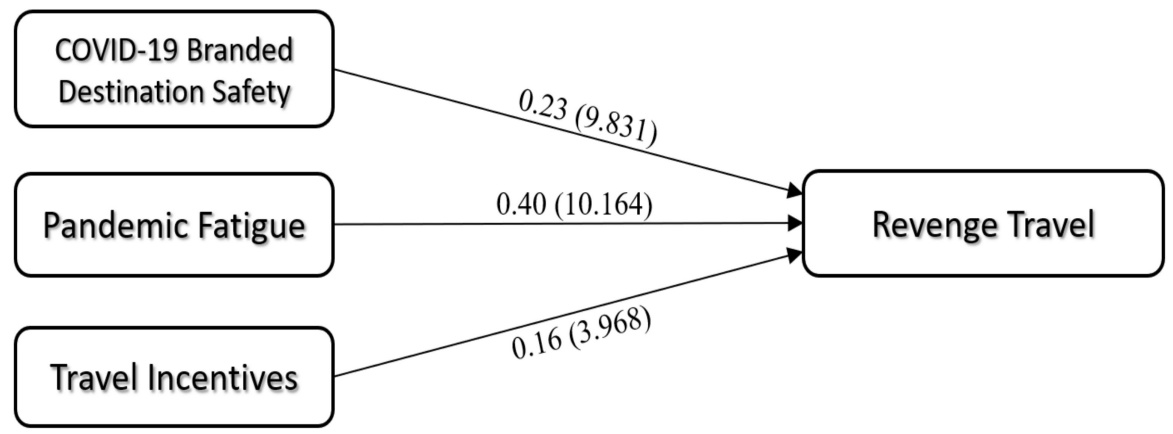

Figure 2. Structural Model 1 (without moderators).

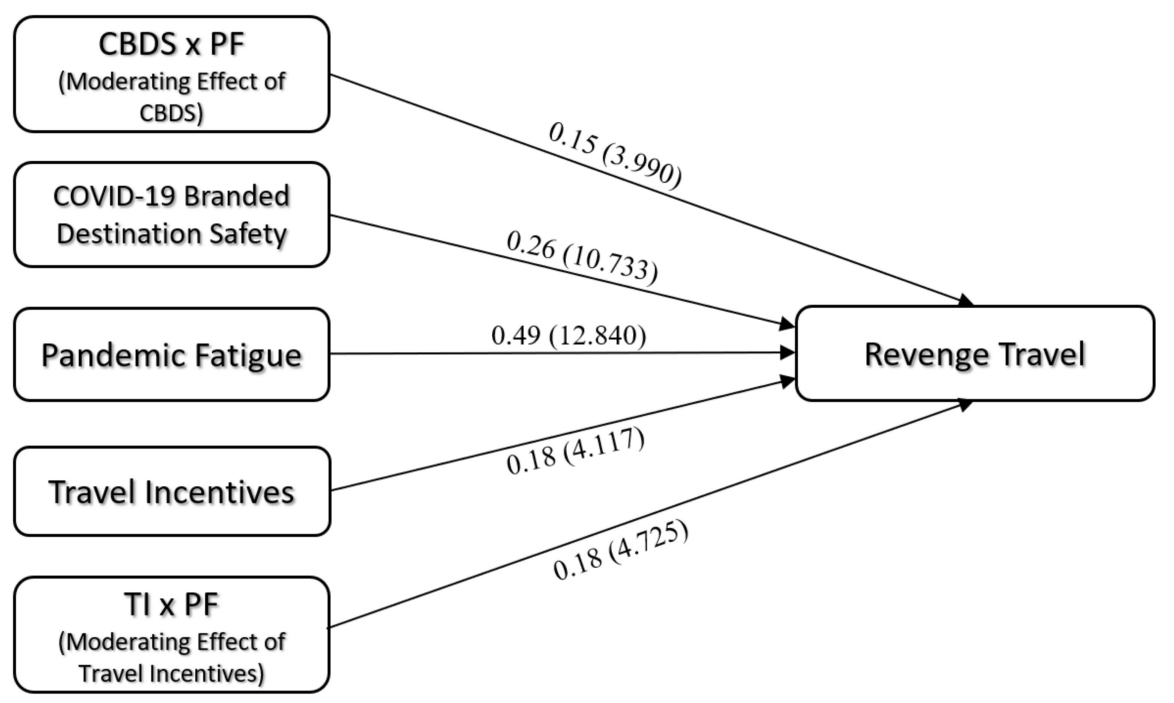

Figure 3. Structural Model 2 (with moderators). 


\section{Discussion}

Although struck badly by the pandemic [37], the tourism industry will bounce back parallel to the relaxation of global health precautions and travel restrictions. Therefore, it is more needed than ever to investigate global tourism trends and the impact of the new normal on the tourism industry. Some recent studies have suggested reviving the tourism industry by attracting pandemic-fatigued and locked-down tourists $[36,90,91]$, whereas Woosnam et al. [92] emphasized the necessity of empathizing with post-pandemic travelers' interest in tourism recovery. However, there is still little known about the factors influencing revenge travel intentions and tourism demand in the post-pandemic era. In this respect, this study empirically tested the relationship between pandemic fatigue and revenge travel by utilizing structural equation modeling. Data were collected from international expats residing in Pakistan, and the findings empirically unveiled that the degree of revenge travel behavior is determined by the expats' pandemic fatigue. This indicates that continuous lockdowns and recurring daily routines have induced boredom, urging individuals to exercise post-pandemic visits both to domestic and international tourism destinations. From this perspective, revenge travel occurs as a counter behavior to make up for the lost time during the lockdowns and curfews.

Although the mainstream literature has already illustrated the negative psychological impacts of the pandemic due to excessive working from home, persisting daily routines, and lockdowns $[3,35,37,38]$, there is no study in the tourism literature assessing the relationship between pandemic fatigue and post-pandemic travel behavior. Thus, this study makes a novel contribution by analyzing the most recent tourism trends that can potentially determine the future of tourism behavior. Furthermore, in the present study, we also analyzed the relevance of travel incentives and CBDS to address the gap in post-pandemic tourism research. In particular, the present study validated the moderating effect of CBDS for the first time in the literature, where CBDS was found to significantly moderate the $\mathrm{PF}$ and RT relationship. This finding confirms that of a prior study, which indicated that individuals' health concerns influence their degree of traveling intentions and tourism choices during the pandemic [92]. Similarly, the mainstream tourism literature before the pandemic also illustrated that tourists' perceptions of a location's safety could substantially influence their travel plans. As a consequence, it can be derived that it is crucial to provide up-to-date and reliable information while promoting destinations in times of crisis $[93,94]$.

In the present study, we also investigated and verified the moderating effect of travel incentives (TIs) on the relationship between pandemic fatigue and revenge travel. The study findings align with those of prior studies that linked TI with tourists' decision-making processes and behavioral motivations. From a broader perspective, revenge travel occurs as a consequence of tourists' changed decision-making processes that have been largely affected by the pandemic conditions. Therefore, borrowing from the theory of planned behavior and incentive theory of motivation, travel incentives can help improve tourists' attitudes towards tourism, which, in return, may result in revenge travel behavior [44,46,57,95].

\subsection{Theoretical Implications}

The aim of the present study was to make a theoretical contribution to the tourism literature by emphasizing some of the key facets (i.e., revenge travel, CBDS, and pandemic fatigue) of post-COVID-19 tourism. This study conceptualizes revenge travel in correlation with emotional and cognitive motives for post-COVID-19 tourism [96]. To that end, this study contributes to the body of existing knowledge by testing and validating a structural model where pandemic fatigue was treated as an antecedent of revenge travel behavior. This finding confirms the theory of planned behavior, which articulates that individuals' perceived control over their behaviors encourages them to initiate an action. In terms of the pandemic, the opening of the borders and the relaxation of travel restrictions might create the feeling that people now have heightened control over their behaviors, which, in return, has resulted in revenge travel. Furthermore, having stayed indoors for a long 
time, pandemic-fatigued individuals are likely to develop a more positive attitude towards traveling [97].

The study findings highlight the positive and significant moderating role of CBDS on the relationship between PF and RT, which empirically suggests that destination branding has become more important than ever during the pandemic. Furthermore, this finding also supplements the protection motivation theory, which manifests that health-linked behaviors are determined as the outcome of individuals' perceived threat and coping ability [98]. In this vein, this study revealed that branding a tourism destination as a place safe from COVID-19 could diminish the perceived threat, and lead to revenge travel behavior. Nevertheless, this is not surprising since the demand for pandemic tourism has been acknowledged to be strongly correlated with tourists' destinations' image and safety perceptions $[99,100]$. In addition, the feeling of safety is a substantial need that usually takes precedence over other needs, including social respect, a sense of belonging and love, and so on $[59,60]$. To sum up, the present study contributes to the destination marketing literature by extending the protection motivation theory to predict revenge travel behavior.

As another contribution, this study provided evidence for the moderating role of travel incentives on the PF and RT relationship. Since the existing literature provides no evidence regarding this impact, this study was deemed an initial effort that verifies that TI can be helpful in revitalizing post-pandemic tourism. This finding confirms the prior tourism literature, which has highlighted that tourism incentives, such as discounts and promotions, increase demand for tourism services [101,102]. In this respect, this study extends the scholarly understanding of the incentive theory of motivation [63], which manifests that people are motivated toward extrinsic rewards and driven away from actions that lead to negative consequences. In particular, the present study theoretically tested and verified that the incentive theory of motivation could be functional to understanding revenge travel in post-pandemic tourism. To sum up, this study combined the most emerging post-pandemic concepts (pandemic fatigue, revenge travel, travel incentives, and COVID-19-branded destination safety) in a comprehensive structural model to address future tourism trends.

Last but not least, despite that the tourism literature has recently pinpointed the vital role of expats for destination recovery, there is still limited research focused on expats' perspectives of tourism [11,103]. In this vein, this study responded to the most recent scholarly call to lay more emphasis on expats as invaluable tourism stakeholders [104], thereby fostering the body of knowledge on expats in the tourism literature [10].

\subsection{Managerial Implications}

Based on the findings, this study offers managerial implications that can be of use when destinations are preparing for the possible spikes in tourism demand after the pandemic. First and foremost, the present study evidently illustrated that pandemic-fatigued individuals are more likely to engage in RT activities [105]. Thus, destinations are advised to gear up to respond to sudden jumps in tourism demand by checking on their existent services and amenities and making necessary adjustments. By doing so, they will not only catch up with an increase in demand but also better respond to changing tourists' expectations [3,91]. Moreover, the findings empirically show that travel incentives, such as discounts or special tour packages, can be of great use to attract the demand of those who were emotionally stressed from spending weeks indoors [106]. At this point, special incentives and tourism packages can be tailored to respond to the niche needs and expectations of revenge travelers. For instance, for vulnerable revenge travelers who are concerned about personal safety and privacy, destinations can offer alternative self-drive tour packages and/or promote less popular rural locations as new tourism centers $[107,108]$. In this way, destinations can better address the changing needs of travelers due to the pandemic, which could contribute to generating positive perceptions and word-of-mouth about the destinations. Especially in a time of crisis, such as the current COVID-19 pandemic, health, safety, and security are always among the top priorities of tourists. Hence, destinations should emphasize their 
highly advanced health infrastructures and precautions while promoting themselves to the next wave of tourism demand [22,109]. The present study can help destinations to familiarize themselves with changing tourism trends, behaviors, and tourists' motivations so as to effectively manage the anticipated tourist influx after the pandemic [6,22]. As another major contribution, the present study has developed new scales (revenge travel, pandemic fatigue, and CBDS) and checked their validity on expats (culturally diverse sample) residing in Pakistan. Gradually becoming a home for global expats, Pakistan hosts almost 3.4 million expats [110], which makes expats' views crucial, especially for the development of both domestic and international tourism [9]. Thus, apart from its theoretical contributions, this study also provides insights into how developing nations can address the emotional motives of international expats to accelerate their tourism recovery and get ready for future tourism demand.

\subsection{Limitations and Future Research}

In this study, data were collected from international expats residing in Pakistan. Since expats have to leave their families, relatives, and friends back in their homelands, they are likely to travel more frequently, at least for personal reasons, than normal residents [111]. Consequently, traveling restrictions and limitations may have heightened impacts on expats' emotional well-being in comparison to normal residents. Expats may also face adaptation problems with the local culture, language, communicational barriers, and so on [112], which could exacerbate the adverse influence of the pandemic. As a result, expats could be more exhausted and experience pandemic fatigue at a greater level than local individuals. Based on the above arguments, the selection of expats to test the research hypotheses constitutes the major limitation of this study. To overcome this limitation, future research should include local residents and analyze whether there is any discrepancy between expats and native citizens' behaviors in post-pandemic tourism. Furthermore, since the pandemic progressed differently across the globe, some destinations were hit worse than others due to the less strictly applied counter-pandemic measures. Future research is suggested to test this study's conceptual model in various countries, where the pandemic has followed different patterns [113]. This approach will not only help to bolster the generalizability of the proposed conceptual model but also lead to destination-wise comparisons [11]. In essence, destinations suffer from unique problems to varying degrees, and thus, need to develop problem-specific solutions to deal with the pandemic. Future studies may concentrate on destination-wise solutions to compensate for the negative economic, social, and cultural impacts of the pandemic. In this vein, future research should investigate the presence of other factors, such as the intensity and/or duration of lockdown, COVID-19 diagnosis in a close family, and so on, which can alter the PF and RT relationships. In essence, revenge travel behavior can also be examined in relation to other concepts, including stress coping strategies, self-protection motives, and individuals' risk orientations, and so on $[114,115]$.

\section{Conclusions}

The aim of this study was to provide theoretical insights into the possible dynamics of the post-pandemic tourism industry. In the research design, the most recent tourism developments and trends (i.e., PF, RT, CBDS) were incorporated and evaluated in a comprehensive structural model. Based on the findings, PF was found to positively affect RT under the positive moderating influences of CBDS and travel incentives. Thus, the results of the present study show that individuals who had to stay indoors during the lockdowns eagerly want to travel to make up for the lost time once the restrictions are relaxed. Destinations are advised to gear up to respond to the sudden demand spikes by checking on and improving their existing facilities and services. In this respect, destinations should analyze revenge travelers' unique needs and wants so as to tailor their services to meet their expectations. While branding themselves, destinations should highlight the fact that they provide safe and reliable tourism services, as it intensifies revenge travelers' motives to travel. To sum 
up, while contributing to the limited literature on pandemic tourism, this study also offers some strategies to tourism professionals and destination marketers.

Author Contributions: Conceptualization, U.Z.; methodology, U.Z.; software, S.H.R.; validation, S.H.R.; formal analysis, S.H.R.; investigation, U.Z., S.A. and S.H.R.; resources, U.Z., S.A. and S.H.R.; data curation, U.Z. and S.H.R.; writing—original draft preparation, U.Z., S.H.R., S.A., P.F. and M.A.; writing-review and editing, U.Z., S.H.R., S.A., P.F. and M.A.; visualization, S.H.R.; supervision, U.Z. and S.H.R.; project administration, U.Z. and P.F. All authors have read and agreed to the published version of the manuscript.

Funding: This research received no external funding.

Institutional Review Board Statement: The study was conducted according to the guidelines of the Declaration of Helsinki and approved by the Institutional Research Ethical Committee of Bahauddin Zakariya University, Multan 66000, Pakistan, and approval Number. MASS310/2021.

Informed Consent Statement: Informed consent was obtained from all subjects involved in the study.

Data Availability Statement: The data that support the findings of this study are available from the corresponding author upon reasonable request due to ethical and privacy restrictions.

Conflicts of Interest: The authors declare no conflict of interest.

\section{Appendix A. Constructs and Scale Items (PF, RT, CBDS, and TI)} Pandemic Fatigue (PF)

1. I worry a lot about my personal and family's safety during this pandemic.

2. I have felt sad and depressed as a result of the pandemic.

3. I am tired of all the COVID-19 discussions in TV shows, newspapers, and radio programs, etc.

4. I am sick of hearing about COVID-19.

5. When friends or family members talk about COVID-19, I try to change the subject because I do not want to talk about it anymore.

6. I feel strained from following all of the behavioral regulations and recommendations around COVID-19.

7. I am tired of restraining myself from saving those who are most vulnerable to COVID-19.

8. I am losing my spirit to fight against COVID-19.

9. I have thoughts that this pandemic will never end soon.

\section{Revenge Travel (RT)}

1. I really miss my travel experiences before the COVID-19 pandemic.

2. I could not travel due to the COVID-19 pandemic.

3. My travel plans got canceled due to the COVID-19 pandemic.

4. I regret that I could not travel due to the COVID-19 pandemic.

5. As soon as the COVID-19 pandemic is over, I want to travel again.

6. As soon as the COVID-19 pandemic is over, I will travel to my favorite destination.

7. I have made some savings to travel again as soon as the COVID-19 pandemic is over.

8. As soon as the COVID-19 pandemic is over, I will stick to my new travel plans.

9. I plan to make up for my missed travel during the COVID-19 pandemic.

COVID-19-Branded Destination Safety (CBDS)

I prefer a tourism destination brand that ensures ...

1. Visitor's health and safety from COVID-19 throughout their stay.

2. Health and safety protocols to control the COVID-19 spread.

3. COVID-19 health screening at airports (e.g., temperature checks, and vaccination proof, etc.).

4. Adequate post-arrival quarantine for visitors.

5. Social distancing measures and wearing of masks.

6. Availability of hand sanitizers in public areas. 
7. Effective contact tracing mechanism for COVID-19.

8. Wider availability of COVID-19 testing facilities.

9. COVID-19 emergency response system (e.g., paramedic services, healthcare facilities, and communications).

10. Mass vaccination campaigns.

Travel Incentives (TI)

I think that the tourism destinations should offer ...

1. Travel promotions to visitors (e.g., discounted, subsidized, or free flights).

2. Free entry to tourist sites (e.g., museums and archeological sites).

3. Free of charge services (e.g., umbrellas, chairs, and sunbeds at famous beaches).

4. Free night(s) of stay for every paid night of accommodation.

5. Vouchers for local attractions.

6. Compensation for travel and medical expenses to visitors who contract COVID-19 at the host destination.

7. Refunds for visitors who bring along their companion (e.g., friends and/or family).

8. Flexible booking and accommodation policies.

9. Visa waiver and visa-free entry.

\section{References}

1. UNWTO. An Inclusive Response for Vulnerable Groups; UNWTO: Madrid, Spain, 2020.

2. Baum, T.; Hai, N.T.T. Hospitality, tourism, human rights and the impact of COVID-19. Int. J. Contemp. Hosp. Manag. 2020, 32, 2397-2407. [CrossRef]

3. Wassler, P.; Fan, D.X.F. A tale of four futures: Tourism academia and COVID-19. Tour. Manag. Perspect. 2021, 38, 100818. [CrossRef]

4. Ghosh, R. What Is Revenge Travel? India Today: New Delhi, India, 2021.

5. Wachyuni, S.S.; Kusumaningrum, D.A. The Effect of COVID-19 Pandemic: How are the Future Tourist Behavior? J. Educ. Soc. Behav. Sci. 2020, 33, 67-76. [CrossRef]

6. Ivanova, M.; Ivanov, I.K.; Ivanov, S. Travel behaviour after the pandemic: The case of Bulgaria. Anatolia 2021, 32, 1-11. [CrossRef]

7. Hussain, A.; Fusté-Forné, F. Post-Pandemic Recovery: A Case of Domestic Tourism in Akaroa (South Island, New Zealand). World 2021, 2, 127-138. [CrossRef]

8. $\quad$ Singh, S. 7 Countires Offering Free Travel to Its Visitors; Ease My Trip: New Delhi, India, 2021.

9. Valek, N. The role of expats, local residents and tourists in defining a destination: A branding case study for Abu Dhabi tourism. Int. J. Sustain. Soc. 2017, 9, 76-93. [CrossRef]

10. Valek, N.; Fotiadis, A. Is tourism really an escape from everyday life? Everyday leisure activities vs leisure travel activities of expats and Emirati nationals living in the UAE. Int. J. Cult. Tour. Hosp. Res. 2018, 12, 238-254. [CrossRef]

11. Aktan, M.; Zaman, U.; Nawaz, S. Examining destinations' personality and brand equity through the lens of expats: Moderating role of expat's cultural intelligence. Asia Pacific J. Tour. Res. 2021, 26, 849-865. [CrossRef]

12. Alvarez, M.D.; Campo, S. The influence of political conflicts on country image and intention to visit: A study of Israel's image. Tour. Manag. 2014, 40, 70-78. [CrossRef]

13. Nadeem, M.A.; Liu, Z.; Xu, Y.; Nawaz, K.; Malik, M.Y.; Younis, A. Impacts of terrorism, governance structure, military expenditures and infrastructures upon tourism: Empirical evidence from an emerging economy. Eurasian Bus. Rev. 2020, 10, 185-206. [CrossRef]

14. Abel, A. The 10 coolest places to go in 2019. Forbes, 12 December 2018.

15. Ahmed, A. Pakistan declared world's third highest potential adventure destination for 2020. Gulf News: Asia, 29 December 2019.

16. EurAsian Times. Pakistan ranked 'The Best Holiday Destination' for 2020 by Leading Travel Magazine. EurAsian Times Desk, 14 December 2019.

17. Khaleej Times. US travel magazine lists Pakistan as top tourist destination for 2020. Islamabaad, 16 December 2019.

18. Jamal, S. Pakistan tops list of world's best travel destination for 2018. Gulf News, 17 November 2017.

19. Ward, L.T.; McComb, J.F. COVID-19 and Tourism in South Asia: Opportunities for Sustainable Regional Outcomes; World Bank: Washington, DC, USA, 2020. [CrossRef]

20. Nabi, I. Coping with COVID-19: The Pakistan Experience; Center for Global Development: Washington, DC, USA, 2020.

21. Polyzos, S.; Samitas, A.; Spyridou, A.E. Tourism demand and the COVID-19 pandemic: An LSTM approach. Tour. Recreat. Res. 2021, 46, 175-187. [CrossRef]

22. Tamitiadini, D.; Hapsari, R.D.V.; Hussein, A.S. Destination branding: Perceived sacredness and spiritual tourism in indonesia amid the COVID-19 pandemic. IRCEB Int. Res. Conf. Econ. Bus. 2021, 2021, 437-449. [CrossRef]

23. World Health Organization. Pandemic Fatigue: Reinvigorating the Public to Prevent COVID-19: Policy Framework for Supporting Pandemic Prevention and Management, Revised version November. (No. WHO/EURO: 2020-1573-41324-56242); Regional Office for Europe: Geneva, Switzerland, 2020. 
24. WHO. Pandemic Fatigue Reinvigorating the Public to Prevent COVID-19; WHO: Geneva, Switzerland, 2020.

25. Labrague, L.J. Pandemic fatigue and clinical nurses' mental health, sleep quality and job contentment during the covid-19 pandemic: The mediating role of resilience. J. Nurs. Manag. 2021, 29, 1992-2001. [CrossRef] [PubMed]

26. Lilleholt, L.; Zettler, I.; Betsch, C.; Böhm, R. Pandemic fatigue: Measurement, correlates, and consequences. PsyArXiv Prepr 2020, 1-36. [CrossRef]

27. MacIntyre, C.R.; Nguyen, P.-Y.; Chughtai, A.A.; Trent, M.; Gerber, B.; Steinhofel, K.; Seale, H. Mask use, risk-mitigation behaviours and pandemic fatigue during the COVID-19 pandemic in five cities in Australia, the UK and USA: A cross-sectional survey. Int. J. Infect. Dis. 2021, 106, 199-207. [CrossRef]

28. Reicher, S.; Drury, J. Pandemic fatigue? How adherence to covid-19 regulations has been misrepresented and why it matters. BMJ 2021, 372, 1-2. [CrossRef]

29. de Smet, A.; Tegelberg, L.; Theunissen, R.; Vogel, T. Overcoming Pandemic Fatigue: How to Reenergize Organizations for the Long Run; McKinsey Co.: Chicago, IL, USA, 2020.

30. Anastasiadou, E.; Anestis, M.C.; Karantza, I.; Vlachakis, S. The coronavirus' effects on consumer behavior and supermarket activities: Insights from Greece and Sweden. Int. J. Sociol. Soc. Policy 2020, 40, 893-907. [CrossRef]

31. Jiaming, F.; Kulbo, N.B.; Liangqiang, L. Coronavirus: Fear appeal favoring purchase behavior towards personal protective equipment. Serv. Ind. J. 2020, 40, 417-490.

32. Ranasinghe, R.; Herath, J.; Nawarathna, D.; Gangananda, N.; Bandara, A.; Pattiyagedara, S. Lockdown Pressure of Corona Pandemic, Tourism Industry Pull, and Individual Travel Push: A Critical Review. Tour. Ind. Pull Individ. Travel Push A Crit. Rev. 2021. [CrossRef]

33. Seraphin, H.; Dosquet, F. Mountain tourism and second home tourism as post COVID-19 lockdown placebo? Worldw. Hosp. Tour. Themes 2020, 12, 485-500. [CrossRef]

34. Sahdel, D.J. Revenge travel' is the phenomenon that could bring back tourism with a bang. Wash. Post 2020, $43,207$.

35. Oktaviani, D.; Sutisna, D. An Analytical Study of The Readiness of Eco-Tourism Based Transactions in The Mount Putri Bandung (Indonesia) Tourism Area. Rev. Int. Geogr. Educ. 2021, 11, 229-234. [CrossRef]

36. Lange, R.; Houran, J.; Tracey, J.B. Many happy returns: Preliminary study on retrospective and prospective experiences of enchantment. Tour. Hosp. Res. 2021, 14673584211035774. [CrossRef]

37. Abdullah, M.N.A. Revenge tourism: Trend or impact post-pandemic COVID-19. In Promoting Creative Tourism: Current Issues in Tourism Research, 1st ed.; Routledge: London, UK, 2021; pp. 623-627.

38. Sudjana, A.A.; Aini, S.N.; Nizar, H.K. Revenge Tourism: Analysis of Tourist Interest Post-COVID-19 Pandemic. Pringgitan 2021, 2, 6. [CrossRef]

39. Séraphin, H.; Zaman, M.; Olver, S.; Bourliataux-Lajoinie, S.; Dosquet, F. Destination branding and overtourism. J. Hosp. Tour. Manag. 2019, 38, 1-4. [CrossRef]

40. Pasquinelli, C.; Trunfio, M.; Bellini, N.; Rossi, S. Sustainability in overtouristified cities? A social media insight into italian branding responses to covid-19 crisis. Sustainability 2021, 13, 1848. [CrossRef]

41. Setiadi, A.; Atma, U.; Yogyakarta, J. City Tourism Branding Resilience During the COVID-19 Pandemic in Yogyakarta, Indonesia. SPATIUM 2021, 44, 1-8. [CrossRef]

42. Morrison, A.M. Destination branding. Mark. Manag. Tour. Destin. 2020, 1, 321-351. [CrossRef]

43. Zou, Y.; Meng, F. Chinese tourists' sense of safety: Perceptions of expected and experienced destination safety. Curr. Issues Tour. 2020, 23, 1886-1899. [CrossRef]

44. Xie, Y.; Danaf, M.; Azevedo, C.L.; Akkinepally, A.P.; Atasoy, B.; Jeong, K.; Seshadri, R.; Ben-Akiva, M. Behavioral modeling of on-demand mobility services: General framework and application to sustainable travel incentives. Transportation 2019, 46, 2017-2039. [CrossRef]

45. Marine-Roig, E.; Huertas, A. How safety affects destination image projected through online travel reviews. J. Destin. Mark. Manag. 2020, 18, 100469. [CrossRef]

46. Azevedo, C.L.; Seshadri, R.; Gao, S.; Atasoy, B.; Akkinepally, A.; Christofa, E.; Zhao, F.; Trancik, J.; Ben-Akiva, M. Tripod: Sustainable Travel Incentives with Prediction, Optimization, and Personalization. In Proceedings of the 97th Annual Meeting of the Transportation Research Board, Washington, DC, USA, 7-11 January 2018; Voume 1, p. 19.

47. Mariano, K. These countries will pay you to travel. Travel Daily, 9 October 2020.

48. STR. Are Travel Incentives Lifting Demand in the Hotel Sector? STR, Inc.: Hendersonville, TN, USA, 2021.

49. Jones, D. These destinations will basically pay you to come visit during the pandemic. The Washington Post, 29 May 2020.

50. Irina, Z. Vacation \& travel incentives around the world right now. BagsAway Passport, 23 July 2020.

51. Murphy, J.F.A. Pandemic Fatigue. Ir. Med. J. 2020, 113, 90. [CrossRef] [PubMed]

52. Zerbe, K.J. Pandemic Fatigue: Facing the Body's Inexorable Demands in the Time of COVID-19. J. Am. Psychoanal. Assoc. 2020, 68, 475-478. [CrossRef] [PubMed]

53. Morgul, E.; Bener, A.; Atak, M.; Akyel, S.; Aktaş, S.; Bhugra, D.; Ventriglio, A.; Jordan, T.R. COVID-19 pandemic and psychological fatigue in Turkey. Int. J. Soc. Psychiatry 2021, 67, 128-135. [CrossRef]

54. Benjamin, S.; Dillette, A.; Alderman, D.H. 'We can't return to normal': Committing to tourism equity in the post-pandemic age. Tour. Geogr. 2020, 22, 476-483. [CrossRef] 
55. Sharma, G.D.; Thomas, A.; Paul, J. Reviving tourism industry post-COVID-19: A resilience-based framework. Tour. Manag. Perspect. 2021, 37, 100786. [CrossRef]

56. Haywood, K.M. A post COVID-19 future-tourism re-imagined and re-enabled. Tour. Geogr. 2020, 22, 599-609. [CrossRef]

57. Ajzen, I. The Theory of Planned Behavior. Organ. Behav. Hum. Perform. 1991, 50, 179-211. [CrossRef]

58. Liu, Y.; Shi, H.; Li, Y.; Amin, A. Factors influencing Chinese residents' post-pandemic outbound travel intentions: An extended theory of planned behavior model based on the perception of COVID-19. Tour. Rev. 2021, 76, 871-891. [CrossRef]

59. Rogers, R.W.; Prentice-Dunn, S. Protection motivation theory. In Handbook of Health Behavior Research: Personal and Social Determinants; Goch., D.S., Ed.; Springer: Berlin/Heidelberg, Germany, 1997; pp. 113-132.

60. Maslow, A.H. Motivation and Personality, 3rd ed.; Harpet \& Row: New York, NY, USA, 1987.

61. Coccia, B.M. Intrinsic and extrinsic incentives to support motivation and performance of public organizations. J. Econ. Bibliogr. 2019, 6, 20-29.

62. Barbara, T.H.; Yen, C.M.; Matthew, B. Gamification in transport interventions: Another way to improve travel behavioural change. Cities 2019, 85, 140-149. [CrossRef]

63. Killeen, P.R. Incentive Theory of Motivation. Neb. Symp. Motiv. 1981, 29, 169-216.

64. Zaman, U.; Aktan, M.; Qureshi, M.G.; Bayrakdaroglu, F.; Nawaz, S. Every storm will pass: Examining expat's host countrydestination image, cultural intelligence and renewed destination loyalty in COVID-19 tourism. Cogent Bus. Manag. 2021, 8, 1969631. [CrossRef]

65. Ekanayake, A.; Amirthalingam, K. Impact of migration of Sri Lankan professionals to Qatar on skill acquisition and brain drain. Migr. Dev. 2020, 9, 1-19. [CrossRef]

66. Baruch, Y.; Holtom, B.C. Survey response rate levels and trends in organizational research. Hum. Relat. 2008, 61, 1139-1160. [CrossRef]

67. Yen, C.H.; Tsaur, S.H.; Tsai, C.H. Destination safety climate: Scale development and validation. J. Travel Tour. Mark. 2021, 38, 303-315. [CrossRef]

68. Rosseel, Y. Small sample solutions for structural equation modeling. In Small Sample Size Solutions, 1st ed.; Routledge: London, UK, 2020.

69. Hoyle, R.H.; Kenny, D.A. Statistical power and tests of mediation. In Statistical Strategies for Small Sample Research; Sage Publications, Inc.: Thousand Oaks, CA, USA, 1999; pp. 195-222.

70. Ullman, J.B.; Tabachnick, B.G.; Fidell, L.S. Using multivariate statistics. Struct. Equ. Model. 2001, 1, 653-771.

71. Tinsley, H.E.; Tinsley, D.J. Uses of factor analysis in counseling psychology research. J. Couns. Psychol. 1987, 34, 414. [CrossRef]

72. Amaro, S.; Seabra, C.; Abrantes, J.L. Comparing CB-SEM and PLS-SEM Results: An empirical example. In Proceedings of the 2nd International Symposium on Partial Least Squares Path Modeling, Seville, Spain, 16-19 June 2015; pp. 1-7.

73. Hair, J.F., Jr.; Matthews, L.M.; Matthews, R.L.; Sarstedt, M. PLS-SEM or CB-SEM: Updated guidelines on which method to use. Int. J. Multivar. Data Anal. 2017, 1, 107. [CrossRef]

74. Rigdon, E.E.; Sarstedt, M.; Ringle, C.M. On Comparing Results from CB-SEM and PLS-SEM: Five Perspectives and Five Recommendations. Mark. ZFP-J. Res. Manag. 2017, 39, 4-16. [CrossRef]

75. Hair, J.F.; Hult, G.T.M.; Ringle, C.M.; Sarstedt, M. A Primer on Partial Least Squares Structural Equation Modeling (PLS-SEM), 2nd ed.; Sage Publications, Inc.: Thousand Oaks, CA, USA, 2017.

76. Zaman, U.; Nadeem, R.D.; Nawaz, S. Examining the effect of xenophobia on 'transnational' mega construction project (MCP) success: Moderating role of transformational leadership and high-performance work (HPW) practices. Eng. Constr. Archit. Manag. 2020, 27, 1119-1143. [CrossRef]

77. Cronbach, L.J. Coefficient alpha and the internal structure of tests. Psychometrika 1951, 16, 297-334. [CrossRef]

78. Kaiser, H.F. A second generation little jiffy. Psychometrika 1970, 35, 401-415. [CrossRef]

79. Snedecor, G.W.; Cochran, W.G. Statistical Methods, 8th ed.; Iowa State University Press: Ames, IA, USA, 1989.

80. Awang, Z.; Afthanorhan, A.; Mohamad, M.; Asri, M.A.M. An evaluation of measurement model for medical tourism research: The confirmatory factor analysis approach. Int. J. Tour. Policy 2015, 6, 29-45. [CrossRef]

81. Corner, S. Choosing the right type of rotation in PCA and EFA. JALT Test. Eval. SIG Newsl. 2009, 13, $20-25$.

82. Fuller, C.M.; Simmering, M.J.; Atinc, G.; Atinc, Y.; Babin, B.J. Common methods variance detection in business research. J. Bus. Res. 2016, 69, 3192-3198. [CrossRef]

83. Brown, T.A. Confirmatory Factor Analysis for Applied Research, 2nd ed.; The Guilford Press: New York, NY, USA, 1960.

84. Bin Mustafa, M.Z.; Bin Nordin, M.N.; Bin Abdul Razzaq, A.R. Structural equation modelling using AMOS: Confirmatory factor analysis for taskload of special education integration program teachers. Univers. J. Educ. Res. 2020, 8, 127-133. [CrossRef]

85. Bentler, P.M. Comparative fit indexes in structural modeling: Adjudging model fit. Psychol. Bull. 1990, 107, 238-246. [CrossRef]

86. Hooper, D.; Coughlan, J.; Mullen, M.R. Structural equation modelling: Guidelines for determining model fit. J. Bus. Res. Methods 2008, 6, 53-60.

87. Hu, L.; Bentler, P.M. Toff criteria for fit indexes in covariancestructure analysis: Conventional criteria versus new alternatives. Struct. Equ. Model. Multidiscip. J. 1999, 6, 1-55. [CrossRef]

88. Blunch, N.J. Introduction to Structural Equation Modeling Using IBM SPSS Statistics and Amos, 1st ed.; Sage Publications, Inc.: Thousand Oaks, CA, USA, 2008. 
89. Blunch, N.J. Introduction to Structural Equation Modeling Using IBM SPSS Statistics and Amos, 2nd ed.; Sage Publications, Inc.: Thousand Oaks, CA, USA, 2013.

90. Hair, J.F.; Gabriel, M.L.; Patel, V.K. AMOS Covariance-based Structural Equation Modeling (CB-SEM): Guidelines on its application as a marketing research tool. Rev. Bras. Mark. 2014, 13, 44-55. [CrossRef]

91. Torres, E.N.; Ridderstaat, J.; Wei, W. Negative affectivity and people's return intentions to hospitality and tourism activities: The early stages of COVID-19. J. Hosp. Tour. Manag. 2021, 49, 89-100. [CrossRef]

92. Woosnam, K.M.; Russell, Z.; Ribeiro, M.A.; Denley, T.J.; Rojas, C.; Hadjidakis, E.; Barr, J.; Mower, J. Residents' pro-tourism behaviour in a time of COVID-19. J. Sustain. Tour. 2021, 1-20. [CrossRef]

93. BChua, L.; Al-Ansi, A.; Lee, M.J.; Han, H. Tourists' outbound travel behavior in the aftermath of the COVID-19: Role of corporate social responsibility, response effort, and health prevention. J. Sustain. Tour. 2020, 29, 879-906. [CrossRef]

94. Sonmez, S.F.; Graefe, A.R. Determining future travel behavior from past travel experience and perceptions of risk and safety. J. Travel Res. 1998, 37, 171-177. [CrossRef]

95. Durocher, J. Recovery marketing: What to do after a natural disaster. Cornell Hotel Restaur. Adm. Q. 1994, 35, 66-71. [CrossRef]

96. Azevedo, L. Modeling travel behavior with on-demand systems: The case of real-time sustainable travel incentives. In Proceedings of the 7th Symposium of the European Association for Research in Transportation, Athens, Greece, 5-7 September 2018; pp. 3-5.

97. Kim, E.E.K.; Seo, K.; Choi, Y. Compensatory Travel Post COVID-19: Cognitive and Emotional Effects of Risk Perception. J. Travel Res. 2021, 00472875211048930. [CrossRef]

98. Meichtry, B.S.; Sugden, J.; Barnett, A. Pandemic Fatigue Is Real-And It's Spreading. 2020, pp. 1-9. Available online: https://jmss.vic.edu.au/wp-content/uploads/2020/12/Pandemic-Fatigue-Is-Real.pdf (accessed on 16 November 2021).

99. Rather, R.A. Demystifying the effects of perceived risk and fear on customer engagement, co-creation and revisit intention during COVID-19: A protection motivation theory approach. J. Destin. Mark. Manag. 2021, 20, 100564. [CrossRef]

100. Rasoolimanesh, S.M.; Seyfi, S.; Rastegar, R.; Hall, C.M. Destination image during the COVID-19 pandemic and future travel behavior: The moderating role of past experience. J. Destin. Mark. Manag. 2021, 21, 100620. [CrossRef]

101. Ahmad, A.; Jamaludin, A.; Zuraimi, N.S.M.; Valeri, M. Visit intention and destination image in post-COVID-19 crisis recovery. Curr. Issues Tour. 2021, 24, 2392-2397. [CrossRef]

102. Park, J.-Y.; Jang, S. Did I get the best discount? Counterfactual thinking of tourism products. J. Travel Res. 2018, 57, 17-30. [CrossRef]

103. Falk, M.; Scaglione, M. Effects of ski lift ticket discounts on local tourism demand. Tour. Rev. 2018, 73, 480-491. [CrossRef]

104. Dutt, C.S.; Harvey, W.S.; Shaw, G. The missing voices in the perceptions of tourism: The neglect of expatriates. Tour. Manag. Perspect. 2018, 26, 193-202. [CrossRef]

105. Poulaki, I.; Nikas, I.A. Measuring tourist behavioral intentions after the first outbreak of COVID-19 pandemic crisis. Prima facie evidence from the Greek market. Int. J. Tour. 2021, 7, 845-860. [CrossRef]

106. Wu, T.; Henneberry, S.R.; Ng'ombe, J.N.; Melstrom, R.T. Chinese Demand for Agritourism in Rural America. Sustainability 2020, 12, 3052. [CrossRef]

107. Li, Z.; Zhang, X.; Yang, K.; Singer, R.; Cui, R. Urban and rural tourism under COVID-19 in China: Research on the recovery measures and tourism development. Tour. Rev. 2021, 76, 718-736. [CrossRef]

108. Rogerson, C.M.; Rogerson, J.M. COVID-19 and changing tourism demand: Research review and policy implications for South Africa. Afr. J. Hosp. Tour. Leis. 2021, 10, 1-21. [CrossRef]

109. Fino, D.; Andrade, C. Routes to Fátima: Tourism and Security issues (a case study). J. Tour. Res. 2018, 19, $197-206$.

110. UNDESA. International Migrant Stock: The 2017 Revision; UNDESA: New York, NY, USA, 2017.

111. Cai, X.; Su, X. Dwelling-in-Travelling: Western expats and the making of temporary home in Guangzhou, China. J. Ethn. Migr. Stud. 2021, 47, 2815-2832. [CrossRef]

112. Ullah, A.A.; Nawaz, F.; Chattoraj, D. Locked up under lockdown: The COVID-19 pandemic and the migrant population. Soc. Sci. Humanit. Open 2021, 3, 100126. [CrossRef]

113. Gokmen, Y.; Baskici, C.; Ercil, Y. The impact of national culture on the increase of COVID-19: A cross-country analysis of European countries. Int. J. Intercult. Relat. 2021, 81, 1-8. [CrossRef] [PubMed]

114. Zheng, D.; Luo, Q.; Ritchie, B.W. Afraid to travel after COVID-19? Self-protection, coping and resilience against pandemic 'travel fear'. Tour. Manag. 2021, 83, 104261. [CrossRef]

115. Parady, G.; Taniguchi, A.; Takami, K. Travel behavior changes during the COVID-19 pandemic in Japan: Analyzing the effects of risk perception and social influence on going-out self-restriction. Transp. Res. Interdiscip. Perspect. 2020, 7, 100181. [CrossRef] 